
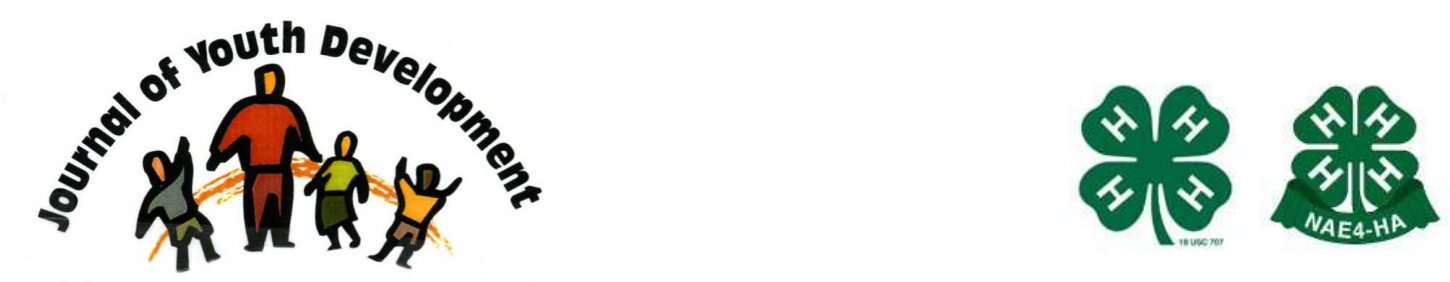

Bridging Research \& Practice

\title{
The Value of Relevant, Project-Based Learning to Youth Development
}

\author{
Kerry Schwartz \\ University of Arizona \\ Department of Agricultural Education \\ Water Resources Research Center \\ Tucson, AZ \\ kschwart@cals.arizona.edu \\ Darcy Tessman \\ 4-H Youth Development \\ University of Arizona, Cochise County \\ Sierra Vista, AZ \\ dtessman@cals.arizona.edu
}

\section{Daniel McDonald}

Family Consumer Health Sciences

University of Arizona, Pima County

Tucson, AZ

mcdonald@cals.arizona.edu 


\title{
JOURNAL OF YOUTH DEVELOPMENT \\ bridging research and practice

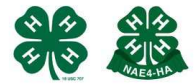

Volume 8, Number 1, Spring 2013

Article 130801PA002

\section{The Value of Relevant, Project-Based Learning to Youth Development}

\author{
Kerry Schwartz, Darcy Tessman and Daniel McDonald \\ University of Arizona
}

\begin{abstract}
Project Based Learning models present authentic learning opportunities with real-life situations, enabling students to set their own learning goals and forge their own relationships (Barab, et al., 2001). The autonomy inherent in this model allows youth to bring their skills and experiences to real situations and to be seen as valued community members. This article describes a project-based learning model involving "externs," who developed and implemented sustainability projects in their communities. Externs worked with Cooperative Extension professionals on locally relevant community projects during the summer of 2011 in three Arizona counties. The project based learning experience had a positive impact on the lives of our three externs.
\end{abstract}

\section{Introduction}

Education theorists argue that the lecture format of pedagogy, that is, a didactic method focusing on memorization of facts, does not lend itself to retaining information beyond examinations as compared to participatory models, which are predominantly inquiry-based (Barab, Hay, Barnett, \& Squire, 2001). Educators and educational institutions are moving towards more participatory, project-based learning models (PBL). PBL models are studentcentered; use group-learning to solve problems (Raisch, Holdsworth, Mann, \& Kabat, 1995); are process-based, working to solve issues that do not have simple answers (Hmelo-Siver, 2004); increase critical thinking, problem-solving, collaborative skills, content knowledge; and escalate motivation and engagement (Brush, \& Saye, 2008). PBL models present authentic learning opportunities with real-life situations, enabling students to set their own learning goals and forge their own relationships (Barab, et al., 2001). The autonomy inherent in this model allows youth to bring their skills and experiences to real situations and to be seen as valued community members. This article describes a project-based learning model involving "externs," who developed and implemented sustainability projects in their communities. 


\section{Background}

First, it might be helpful to the reader to understand what we mean by "externship" as opposed to "internship." The key distinction between a typical internship and the modified definition of externship is that students bring passion and particular skills and apply them in service to their communities through University of Arizona Cooperative Extension, as a part of the outreach mission of land grant universities.

The overall purpose of the Externships in Sustainability Program was to create opportunities for university students to bring their experience, skills, and enthusiasm to their communities through innovative sustainability projects. Externs applied their own knowledge, organizational and problem-solving skills to bring a local project to fruition. Externs worked with Cooperative Extension professionals on locally relevant community projects during the summer of 2011 in three Arizona counties. Data collection was conducted in the fall and winter 2011-2012. The projects are briefly described below followed by the results of a qualitative analysis of the data, specifically focusing on how the experiences of the externs and their supervisors aligned with the theoretical underpinnings of project-based learning models.

\section{Graham County}

The extern in Graham County investigated and documented findings on the current water and irrigation systems at the Discovery Park complex in Safford, a facility administered by Eastern Arizona College. The extern planned, coordinated, and installed a water-harvesting demonstration tank on one of the buildings, and developed a xeriscape plan for the threebuilding complex and amphitheater. As a result of this project the facility collects 4,000 gallons of rainwater annually which is used to water the outdoor gardens.

\section{Cochise County}

The extern in Cochise County coordinated and taught six classes at the Summer Gardening Institute for Teachers held in Sierra Vista. Workshops were conducted on Rainwater Harvesting, Gardening, Nutrition, Entrepreneurship, Creating Gardens at Your School, and Integrating Technology with School Gardens. Teachers participating in the summer institute went on to instruct approximately 500 youth annually using this locally relevant information.

\section{Gila County}

The Gila County extern developed and implemented a Farmers' Market in Globe. The extern implemented market promotion activities including maintaining a Facebook page, writing a weekly newsletter, submitting articles to the local newspapers, and hanging posters. In addition to assisting vendors and the market manager with logistical matters, the extern also conducted children's activities and arranged for weekly guest speakers. The extern was also responsible for developing, implementing, and analyzing a survey of market vendors to track sales and attendance.

\section{Method}

To better understand what impact the externship had on the students and participating supervisors, in-depth interviews were conducted with key informants. A set of interview questions and an interview protocol were developed. Three externs and their supervisors were interviewed six months after participating in the externship pilot project. Three members of the sustainability team, consisting of Cooperative Extension professionals, conducted the interviews, each interviewing one extern and their respective supervisor separately. Interviews were 
conducted by phone at the participant's convenience. Notes were taken during the interview and no recordings were made. Notes were then transcribed and distributed to a team of six sustainability team members who conducted a content analysis of the transcripts (Hsieh, \& Shannon, 2005). The evaluation was submitted through the University of Arizona Institutional Review Board.

\section{Interview Questions}

A set of open-ended interview questions was developed by the members of the sustainability team who conducted the interviews. Some questions were asked of both supervisor and extern, and some were unique to one or the other as noted below:

- (J) - Joint question

- (PS) - Project Supervisor question

- (E) - Extern question

\section{Questions:}

1. Briefly describe the externship project you participated in. (J)

2. What worked well? Why do you think that it worked well? (J)

3. How did this position/person influence overall programming and impact in the county? (PS)

4. How did this opportunity change (or influence) what programming you are doing? (PS)

5. What does it mean to be working in your own community on a sustainability project? (E)

6. How did you incorporate sustainability/sustainable practices? (E)

7. How has this experience influenced school decisions/career path? (E)

8. How has this experience changed (or influenced) your definition of sustainability? (J)

9. What does this mean in your community and the broader university around the issue/topic of sustainability? (J)

10. What are the next steps? (J)

A protocol for analyzing the data was established based on the recommendations of TaylorPowell, \& Renner (2003): becoming familiar with the data; organizing responses by the interview questions; identifying categories by emerging themes (circling or highlighting key words or phrases) and refining those to sub-categories when appropriate; identifying commonalities among categories and sub-categories by making notes in margins or columns; and reaching consensus on the emerging themes and interpretation of the data through group discussion.

\section{Results}

Three primary themes emerged from the analysis of the data:

- Personal impact (e.g., independence and self-reliance of extern)

- Extension and Community impact (e.g., building ties to the community; building capacity; and further establishing Extension identity in communities)

- Sustainability impact (e.g., awareness of sustainability issues; and evidence of behavior change)

For the purposes of this article we will focus on the "personal impact" theme and the six subthemes that emerged from the extern and faculty mentor interviews:

1. Self-reliance and Responsibility

2. Mutual Relationships

3. The Value of Hands-on Relevant Learning 

4. External Recognition of Expertise
5. Change in Identity
6. Raising Awareness of Sustainability

The themes that emerged from this analysis align with project-based learning themes including self-reliance, responsibility, mutual relationships, multigenerational involvement, hands-on relevance, ownership, and real-world action. Below we illustrate these themes with the words of the externs.

\section{Self-reliance and Responsibility}

According to project-based learning approaches, projects are based on challenging questions or problems and give students the opportunity to work relatively autonomously over extended periods of time (Jones, Rasmussen, \& Moffitt, 1997; Thomas, Mergendoller, \& Michaelson, 1999). For the externs involved in this program, a key component of the experience had to do with the autonomy they were given and the responsibility that was entrusted to them. With strong mentorship available when needed, externs learned to organize themselves, manage their time, and move forward according to a plan. Flexibility and effective problem-solving, sometimes in the moment, were invaluable experiences for the externs. One extern commented, "This was the first job that I'd really had and it was cool to have assistant manager responsibility. It's great to know that I could be a manager. I dealt with disgruntled customers too and learned this skill."

\section{Mutual Relationships}

The mentor-extern relationship proved to be of great importance to the externs. Faculty members were able to strike that balance between guidance and fostering independence. They became facilitators of learning rather than the instructors. An extern said of working with her mentor, "She set me lose and I ended up doing more than I was told. I put my own ideas out there. I liked the learning technique."

\section{The Value of Hands-on Relevant Learning}

Nationwide, the thrust in education is toward the use of real world relevancy to stimulate authentic learning that cuts across subject areas. Project-Based Learning pedagogy does this. According to the Buck Institute for Education, (2003), "evidence shows that PBL enhances the quality of learning and leads to higher level cognitive development through students' engagement with complex novel problems" (p. 6). All externs expressed the personal value of their hands-on learning experience. One extern said, "I used what I learned in Extension and applied it to advertising in my own work."

\section{External Recognition of Expertise}

All externs expressed their surprise and delight at the recognition that they received from adult mentors and community members. Self-recognition of expertise is also embodied in one extern's statement, "I can't express enough the experience that he gave me. I've always been managed and never had the opportunity to develop a whole program with all the pieces by myself." The self-recognition of expertise enables youth to shift toward teaching, effective communication of that expertise, and ultimately leadership.

\section{Change in Identity}

Career-ready means more than having mastered content and practice. It also means that a person has interpersonal, communication, project, and time management skills to name a few. Employers are seeking multifaceted and multi-competent grads and emphasize the importance 
of making new discoveries and applying personal skills (McWilliam, Poronnik, \& Taylor, 2008). As a result of the externship experience, one of the externs has taken on a new identity, explaining: "... now I am recognized as a student in the UA making a change. I am an educated person working in the community and now I'm recognized as an adult working for the community." For another extern the experience was life-changing, stating: "The Externship changed my view a lot-it got me interested and caused me to change my major. It opened my eyes and made me want to bring it (sustainability) back to my community."

\section{Raising Awareness of Sustainability}

Externs were better able to talk about sustainability after their experience than they were prior to their externship. On the concept of sustainability two of the externs described it this way, "It's more out of the box thinking style that people don't always do" and "It's the ability to selfsustain." Even an Extension faculty's viewpoint shifted during the implementation of the sustainability projects: "It (the project) really showed me that it's all about community effort. There are farmer-buyer connections that are important. Everyone in the community has a role for sustainability to happen. It's creating healthy community, not solely relying on outside folks." According to Monroe, Andrews, \& Biedenweg (2008), "When youth develop a community service project and participate in the selection and design of their activity, for example, they are likely to become more efficacious, empowered and committed as they improve their community" (p. 233).

\section{Conclusions}

Relevant, authentic projects offer invaluable learning experiences to today's youth. That experience is enhanced when youth are entrusted with the development and implementation of the project from the beginning. As illustrated above, many of the themes that emerged from this analysis are tenets of project-based learning including self-reliance, responsibility, mutual relationships, multigenerational involvement, hands-on relevance, ownership and real-world action. The project based learning experience had a positive impact on the lives of our three externs. These projects also built in vital workplace skills and lifelong habits of learning and enabled externs to address community issues, explore careers, interact with adult mentors, use technology, and engage with community audiences.

\section{Implications}

The four essential elements of positive 4-H youth development (mastery, belonging, independence, and generosity) provide a theoretical framework for the project-based learning delivery methodology. The authors of this article recommend that this methodology be utilized more often by Extension professionals to engage youth in developing life skills such as problemsolving, critical thinking, and collaboration: skills needed to successfully transition to adulthood. We believe that adhering to the project-based learning pedagogy can lend structure to instruction and further optimize the benefits.

The strong theoretical framework in combination with the comprehensive methodology allow for wide duplication of the Externships in Sustainability Program to any university extension program across the country. The Program can also be readily adapted to other content areas and settings.

This program would benefit from research that fine-tunes various aspects of the model. One further assessment would be to document and assess the mentorship provided to ascertain the 
right balance between guidance and fostering independence. Guidelines for mentor intervention, based on concepts of youth adult partnerships, would help to establish when it is appropriate for adult supervisors to provide more direct instruction to facilitate the progression of project-based learning in a given time-frame. Additional research on the required skill set and maturity level for the externs to ensure project success would also strengthen this approach to youth programming.

\section{References}

Barab, S.A., Hay, K.E., Barnett, M.G., \& Squire, K. (2001). Constructing virtual worlds: Tracing the historical development of learner practices/understandings. Cognition and Instruction, $19(1), 47$.

Brush, T., \& Saye, J. (2008). The effects of multimedia-supported problem-based inquiry on student engagement, empathy, and assumptions about history. The Interdisciplinary Journal of Problem-based Learning, 2(1), 25.

Buck Institute for Education. (2003). Project Based Learning Handbook: A Guide to StandardsFocused Project Based Learning for Middle and High School Teachers, ISBN 0-9740343-0-4.

Hmelo-Silver, C.E. (2004). Problem-based learning: What and how do students learn? Educational Psychology Review, 16(3), 31.

Hsieh, H., \& Shannon, S.E. (2005). Three approaches to qualitative content analysis. Qualitative Health Research, 15, 1277.

Jones, B.F., Rasmussen, C.M., \& Moffitt, M.C. (1997). Real-life problem solving.: A collaborative approach to interdisciplinary learning. Washington, DC: American Psychological Association.

McWilliam, E., Poronnik, P., \& Taylor, P. (2008). Redesigning Science Pedagogy: Reversing the Flight From Science. Journal of Science Education Technology, 17, 226-235.

Monroe, M., Andrews, E., \& Biedenweg, K. (2008). A Framework for Environmental Education Strategies. Applied Environmental Education and Communication 6,205-216.

Raisch, D.W., Holdsworth, M.T., Mann, P.L., \& Kabat, H.F. (1995). Incorporating problembased, student-centered learning into pharmacy externship rotations. American Journal of Pharmaceutical Education, 59, 8.

Taylor-Powell, E., \& Renner, M. (2003). Analyzing Qualitative Data (G3658-12). University of Wisconsin-Extension. Retrieved from: http://learningstore.uwex.edu/assets/pdfs/g3658-12.pdf

Thomas, J.W., Mergendoller, J.R., \& Michaelson, A. (1999). Project-based learning: A handbook for middle and high school teachers. Novato, CA: The Buck Institute for Education.

(C) Copyright of Journal of Youth Development Bridging Research and Practice. Content may not be copied or emailed to multiple sites or posted to a listserv without copyright holder's express written permission. Contact Editor at: patricia.dawson@oregonstate.edu for details. However, users may print, download or email articles for individual use.

ISSN 2325-4009 (Print); ISSN 2325-4017 (Online) 